\title{
A Preliminary Feasibility Assessment of the RESNET HERS Index as an Alternative Compliance Path for the IECC
}

ZT Taylor

$S$ Goel

December 2013

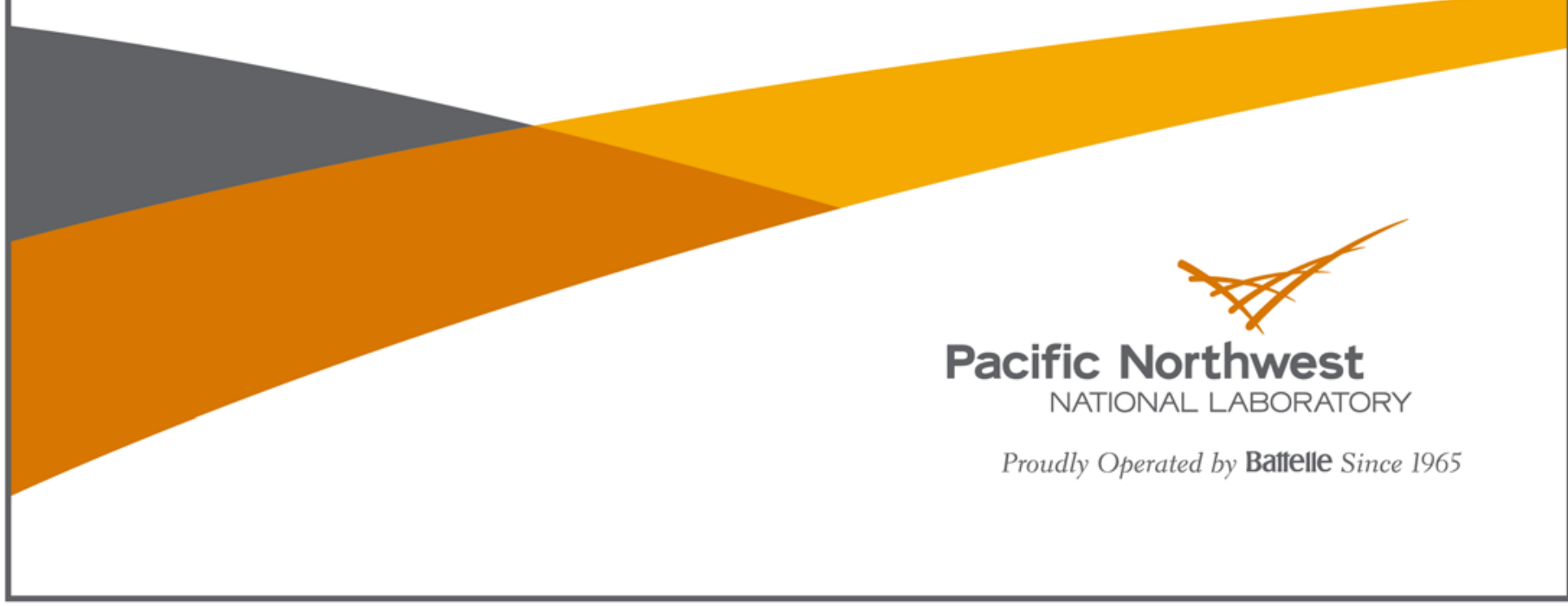




\title{
DISCLAIMER
}

This report was prepared as an account of work sponsored by an agency of the United States Government. Neither the United States Government nor any agency thereof, nor Battelle Memorial Institute, nor any of their employees, makes any warranty, express or implied, or assumes any legal liability or responsibility for the accuracy, completeness, or usefulness of any information, apparatus, product, or process disclosed, or represents that its use would not infringe privately owned rights. Reference herein to any specific commercial product, process, or service by trade name, trademark, manufacturer, or otherwise does not necessarily constitute or imply its endorsement, recommendation, or favoring by the United States Government or any agency thereof, or Battelle Memorial Institute. The views and opinions of authors expressed herein do not necessarily state or reflect those of the United States Government or any agency thereof.

\author{
PACIFIC NORTHWEST NATIONAL LABORATORY \\ operated by \\ BATTELLE \\ for the \\ UNITED STATES DEPARTMENT OF ENERGY \\ under Contract DE-AC05-76RL01830
}

Printed in the United States of America

Available to DOE and DOE contractors from the

Office of Scientific and Technical Information,

P.O. Box 62, Oak Ridge, TN 37831-0062;

ph: (865) 576-8401

fax: $(865) 576-5728$

email: reports $a$ adonis.osti.gov

Available to the public from the National Technical Information Service

5301 Shawnee Rd., Alexandria, VA 22312

ph: (800) 553-NTIS (6847)

email: ordersantis.gov <http://www.ntis.gov/about/form.aspx>

Online ordering: http://www.ntis.gov 


\section{A Preliminary Feasibility Assessment of the RESNET HERS Index as an Alternative Compliance Path for the IECC}

ZT Taylor

S Goel

December 2013

Prepared for

the U.S. Department of Energy

under Contract DE-AC05-76RL01830

Pacific Northwest National Laboratory

Richland, Washington 99352 



\section{Summary}

This analysis provides a limited evaluation of the relationship between the Residential Energy Services Network (RESNET) Home Energy Rating System (HERS) Index and the simulation-based performance approach used in the 2012 International Energy Conservation Code (IECC). Not all differences between the approaches are analyzed here; only a few distinctions considered likely to result in quantifiable differences in the outcomes of the two approaches and for which available studies have not quantified those differences. This analysis establishes, for a single-family residence with gas heat and a crawlspace foundation, a set of climate-zone-specific, Corresponding HERS Index values that could be used to inform the development of a HERS-based compliance path in the IECC.

Although primarily a prescriptive code, the IECC allows compliance through a performance-based approach that compares the energy performance of a proposed home to that of a similar home built to meet the code's prescriptive requirements. Similarly, the HERS Index gives an analyzed home a performance rating based on its energy performance relative to a defined reference home of similar size and configuration. Calculation of the HERS Index is based on a specialize metric called the normalized Modified End-Use Load (nMEUL).

This analysis compares the two approaches to characterizing a candidate home's energy performance to determine the appropriateness of adding a compliance path based on the HERS Index to the IECC. Energy analyses for both the IECC and the HERS Index have been carried out for the U.S. Department of Energy single-family prototype for 15 climate locations to evaluate the correlation between the HERS rule set and the 2012 IECC performance path approach (Taylor et al. 2012).

The results of this analysis indicate that, for the single-family prototype analyzed, the HERS Index is reasonably well correlated with the energy-performance calculation defined by the 2012 IECC performance path. Differences in the way the two calculation metrics are defined result in HERS Index values corresponding to IECC compliance- that differ somewhat from what might be expected based on the respective energy code baselines inherent in the two metrics. However, the corresponding values differ in ways that are systematic and rational, and that pose no inherent problem in using a HERS Index as an alternative code compliance path provided the differences are accounted for in designing the path.

Differences in how the two metrics define heating and cooling setpoints were found to result in minimal differences in the performance of IECC-compliant homes. Differences in mechanical ventilation assumptions can result in differences in Corresponding HERS Index values between one and almost six points. These differences are of concern only if a jurisdiction were to eliminate or fail to enforce the 2012 IECC requirement for mechanical ventilation. Finally, differences in the treatment of automatic setback thermostats result in differences of one to two points on the HERS Index scale and need to be considered in setting Corresponding HERS Index values.

Several differences between the two metrics were not evaluated in this analysis, including differences in how equipment efficiencies, window-area assumptions, fuel types, building size, and building type are considered. Examination of these and other differences has been left for future work. 



\section{Acronyms and Abbreviations}

$\mathrm{ACH}$

AFUE

ASHRAE

CFA

DOE

EF

EPA

HERS

HVAC

IECC

nMEUL

RESNET

SEER

SHGC

SAF

SRD air changes per hour

annual fuel utilization efficiency

American Society of Heating, Refrigerating and Air-Conditioning Engineers

conditioned floor area

U.S. Department of Energy

energy factor

Environmental Protection Agency

Home Energy Rating System

heating, ventilating, and air-conditioning

International Energy Conservation Code

normalized Modified End-Use Load

Residential Energy Services Network

seasonal energy efficiency ratio

solar heat gain coefficient

size adjustment factor

standard reference design 



\section{Contents}

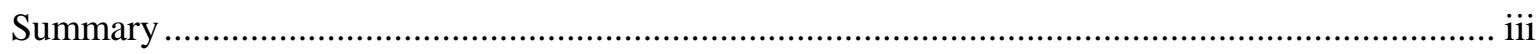

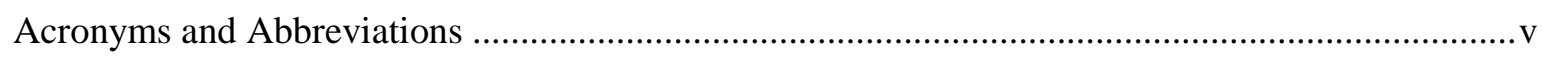

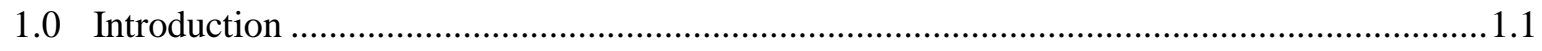

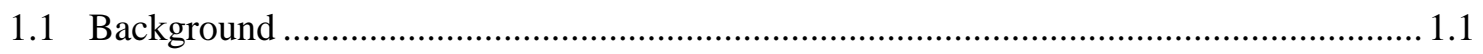

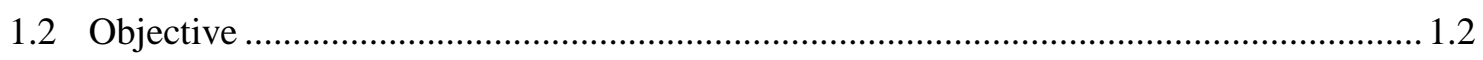

2.0 Comparing the RESNET HERS Index and the 2012 IECC ................................................

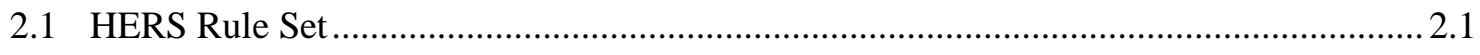

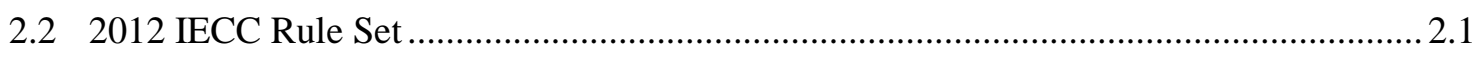

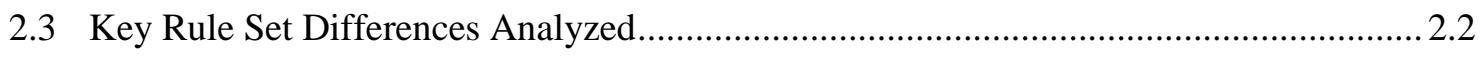

2.3.1 Mechanical Ventilation .................................................................................2.2

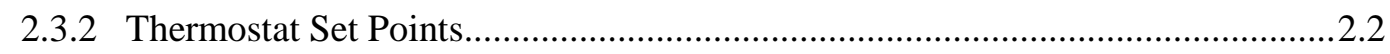

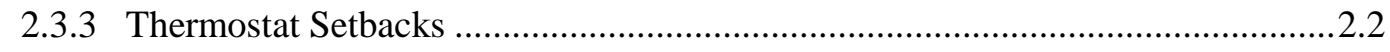

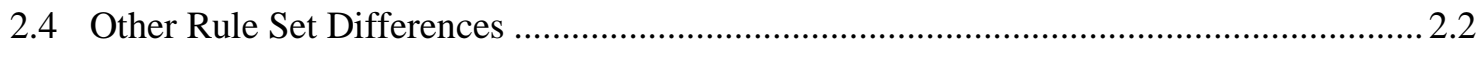

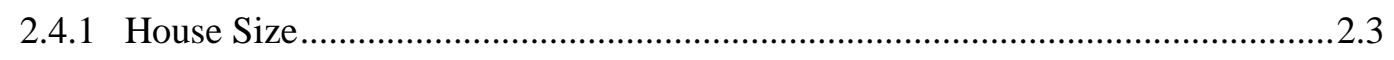

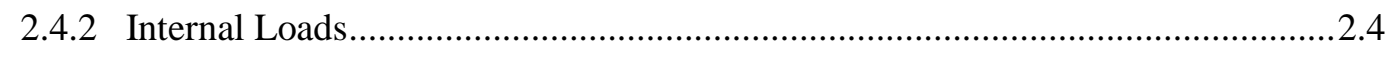

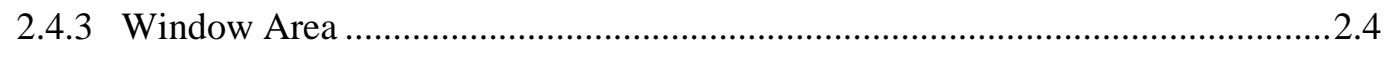

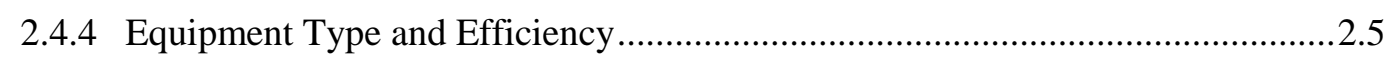

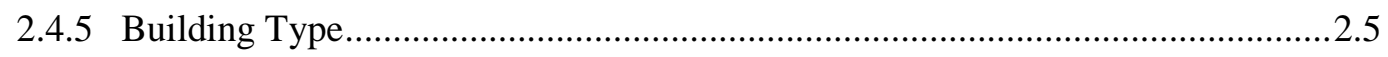

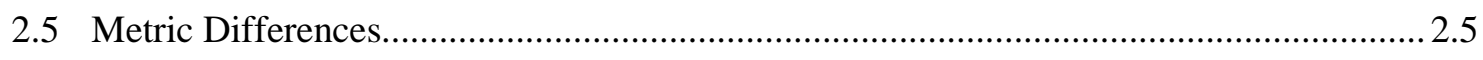

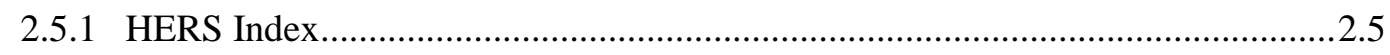

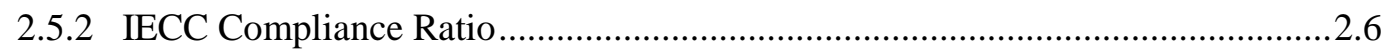

2.6 Interpreting the Correlation between the HERS Index and the IECC Compliance Ratio. 2.6

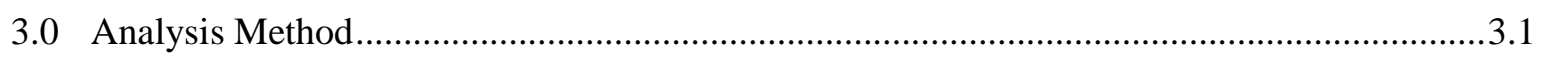

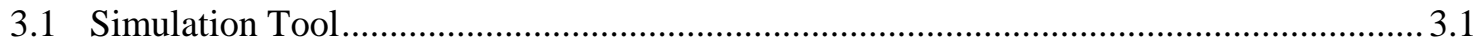

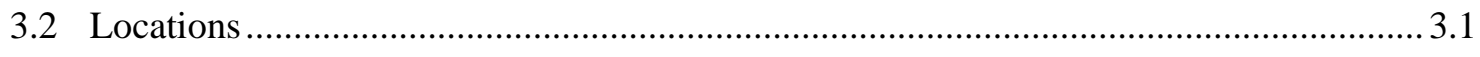

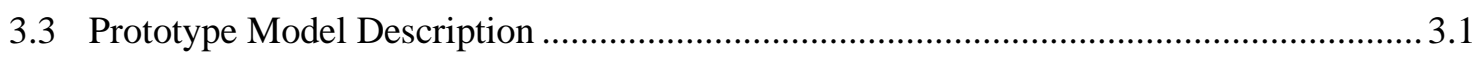

3.4 Assumptions for Evaluated Homes ............................................................................ 3.2

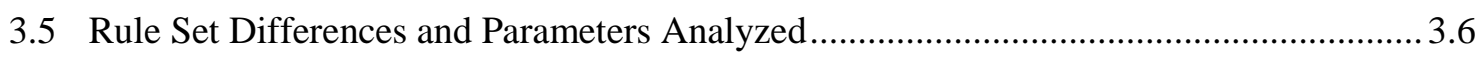

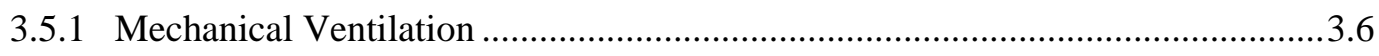

3.5.2 Thermostat Setpoints................................................................................... 3.10

3.5.3 Thermostat Setbacks .................................................................................... 3.13

4.0 Results, Conclusions, and Recommendations ............................................................... 4.1

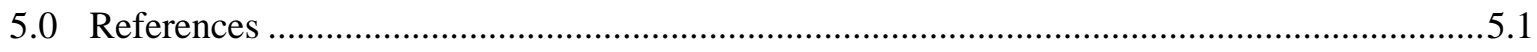




\section{Figures}

Figure 2.1. Energy Star SAF Applied to Corresponding HERS Index Values with a 2400-ft2 Baseline 2.4

Figure 2.2. Hypothetical Perfect Relationship between the 2012 IECC Compliance Ratio and the HERS Index

Figure 3.1. 2012 IECC Compliance Ratio versus HERS Index for 33 Test Cases in 15 Locations

Figure 3.2. 2012 IECC Compliance Ratio versus HERS Index by Climate Zone and Moisture Regime

Figure 3.3. Energy Impact of Mechanical Ventilation on the HERS Reference Home

Figure 3.4. 2012 IECC Compliance Ratio versus Ventilation-Modified HERS Index by Climate Zone and Moisture Regime

Figure 3.5. Variation in Energy Use Due to Temperature Set Points

Figure 3.6. 2012 IECC Compliance Ratio versus Setpoint-Modified HERS Index by Climate Zone and Moisture Regime

Figure 3.7. Variation in Energy Use Due to Thermostat Setbacks

Figure 3.8. 2012 IECC Compliance Ratio versus HERS Index for Homes with Automatic Setback Thermostats by Climate Zone and Moisture Regime

\section{Tables}

Table 3.1. Climate Locations Used for Analysis

Table 3.2. Ranges of Component Characteristics Used for 33 Prototype Configurations

Table 3.3. Comparison of Corresponding HERS Index Values with and without Mechanical Ventilation in the HERS Reference Home

Table 3.4. Comparison of Corresponding HERS Index Values with and without Adjustment to Thermostat Setpoints in the HERS Reference Home

Table 3.5. Comparison of Corresponding HERS Index Values with and without Automatic Setback Thermostats in the HERS Rated Home

Table 4.1. Preliminary Corresponding HERS Index Values 


\subsection{Introduction}

\subsection{Background}

The International Energy Conservation Code (IECC) Simulated Performance Alternative (Section R405 of the 2012 IECC) compares a proposed design against a standard reference design (SRD) that exactly meets the code's prescriptive requirements. Compliance requires that the estimated energy cost of the proposed home be no more than the estimated energy cost of the SRD. The IECC does not concern itself with the magnitude of any estimated difference in energy cost between the two homes, only with the sense of the comparison. However, for this analysis a Compliance Ratio has been defined to facilitate quantitative comparisons with the Residential Energy Services Network (RESNET) Home Energy Rating System (HERS) Index (RESNET 2013). The Compliance Ratio is defined as the energy cost of a candidate home (called the Proposed Design) divided by the energy cost of the 2012 IECC SRD. Consequently, a Compliance Ratio of 1.0 represents a minimally compliant home, while lower numbers indicate better performance and higher numbers represent worse performance.

The 2012 IECC defines energy performance in terms of estimated annual energy cost or annual source energy. The code covers heating, cooling, water-heating, and lighting end uses, and allows no credit in the performance path for changes to the lighting end use or to improvements in equipment efficiency. The IECC contains a table of specifications that govern the various simulation assumptions necessary for estimating annual energy performance.

The HERS Index is a rating that compares a candidate home (called the Rated Home) against a reference home known as the HERS Reference Home or the "American Standard New Home." The overall energy performance of the HERS Reference Home is approximately based on the 2006 IECC. The HERS Index is a ratio defined such that the HERS Reference Home has a HERS Index score of 100, while a net-zero energy home has a HERS Index score of zero. The lower the index number for a home, the more energy efficient it is compared to the HERS Reference Home. Each one-point decrease in the HERS Index corresponds to a nominal 1-percent reduction in energy performance compared to the HERS Reference Home.

RESNET defines a HERS "rule set" that must be used in estimating the energy performance of the HERS Reference Home and the Rated Home. The HERS rule set differs from the IECC methodology in terms of the energy performance metric and the energy end uses included in the calculation. The HERS Index is based on a RESNET-defined performance metric known as the normalized Modified End-Use Load (nMEUL) (Fairey et al. 2000). The nMEUL was designed to allow the same HERS Index scale to apply to homes using any fuel and equipment type for heating. Several beyond-code programs have accepted HERS or a modified version of HERS as a metric of energy efficiency and program qualification or compliance. The HERS Index allows a broader scope of house features to receive performance credit than does the IECC. 


\subsection{Objective}

The objective of this analysis is twofold:

1. Evaluate how the HERS Index and the 2012 IECC Compliance Ratio vary with changes in building characteristics to determine whether the two are sufficiently similar to support the creation of a HERS compliance path in the IECC.

2. If so, identify a preliminary HERS Index value for each climate zone that could be considered IECC complying.

The first objective involves a qualitative assessment of the HERS Index definition, rule set for defining the HERS Reference Home, and procedure for comparing it against the Rated Home; a similar assessment of the 2012 IECC SRD and proposed design requirements; and a quantitative assessment of the differences between the two. A key outcome of this step is a tested methodology for consistently comparing these very different performance metrics.

The second objective involves assessing the significant differences between the HERS Index and the 2012 IECC Compliance Ratio and identifying a specific HERS Index for each climate zone that would confidently result in energy performance equal to or better than that resulting from the IECC performance path. Because this analysis covers only a small subset of known differences between the two metrics, the Corresponding HERS Index values produced here are illustrative, but they should be interpreted in the limited context of house characteristics evaluated and in concert with other studies of HERS Index behavior with changing building characteristics.

These analyses were carried out using the energy analysis procedures outlined for 15 climate locations and the single-family prototype building in the U.S. Department of Energy's (DOE's) Methodology for Evaluating Cost-Effectiveness of Residential Energy Code Changes (Taylor et al. 2012), except for modifications needed to match HERS or IECC rule sets. 


\subsection{Comparing the RESNET HERS Index and the 2012 IECC}

HERS standards in RESNET and the 2012 IECC performance path both define a set of rules for comparing a candidate home with a baseline home. The two approaches are based on different baseline energy efficiency assumptions, use different metrics of comparison, and have different terminology, but the fundamental premises are similar. The HERS and 2012 IECC rule sets are described in the following sections.

\subsection{HERS Rule Set}

The HERS Reference Home is based approximately on the 2006 IECC and is geometrically identical to the Rated Home. As specified, the reference home is wood frame construction with an 18-percent window-floor ratio. All opaque envelope assemblies and vertical fenestration are required to comply with specified U-factor and solar heat gain coefficient (SHGC) values. Minimum ventilation rates are specified for attics and crawlspaces. The envelope air exchange rate is specified at 8.9 air changes per hour at $50 \mathrm{~Pa}$ (ACH50) for all climate zones and does not include the mechanical ventilation rate, irrespective of the provisions in the Rated Home. If the Rated Home is equipped with a mechanical ventilation system, the HERS Reference Home accounts for the additional fan energy use (based on the conditioned floor area and number of bedrooms), but not for the additional air exchange rate. Thus, the Rated Home is penalized for the thermal impact of ventilation. System efficiencies are specified at the prevailing federal minimum requirements for heating, cooling, and water-heating systems. The HERS Reference Home is required to be modeled with a manual thermostat having constant setpoints of $78^{\circ} \mathrm{F}$ for cooling and $68^{\circ} \mathrm{F}$ for heating.

The Rated Home is simulated as built (or as designed). The air exchange rate is required to be determined by a blower door test in accordance with the procedure specified in the 2001 ASHRAE Handbook: Fundamentals (ASHRAE 2001). Internal gains are required to be the same as in the reference home unless high-efficiency appliances are used, in which case the internal loads are determined through procedures specified by the standards. Annual lighting energy is modified in accordance to the fraction of energy-efficient lighting used.

\subsection{IECC Rule Set}

Like the HERS rule set, the 2012 IECC defines its SRD as geometrically identical to the proposed house. It requires wood frame construction with vented attics for the SRD. It restricts the window area to 15 percent of the conditioned floor area and specifies U-factor and SHGC requirements for vertical fenestration. Infiltration is required to be specified at 5 ACH50 for Climate Zones 1 and 2, and 3 ACH50 for Climate Zones 3 through 8. Mechanical ventilation is mandatory for the 2012 IECC and the baseline home is required to account for the increased air exchange rate, thus not penalizing a proposed home for the thermal impact of ventilation. The 2012 IECC performance path does not consider end uses other than heating, cooling, and domestic hot water; hence, internal gains are specified as a total heat gain per day and are required to be the same in the standard reference and proposed designs. Equipment efficiencies are required to be the same for both the standard reference and proposed designs, with 
minimum efficiencies in accordance to the prevailing federal minimum efficiency requirements. The $\mathrm{SRD}$ is required to be simulated with a manual thermostat with cooling setpoint at $75^{\circ} \mathrm{F}$ and heating setpoint at $72^{\circ} \mathrm{F}$.

\subsection{Key Rule Set Differences Analyzed}

The HERS rule set differs from the IECC in a number of details. This analysis examines three such differences for which existing studies have not quantified the correlation between the HERS Index and the IECC performance path. These differences are summarized here.

\subsubsection{Mechanical Ventilation}

For a Rated Home that includes mechanical ventilation, the HERS rule set does not account for the increased air exchange rate due to mechanical ventilation in the reference home, although it does account for the increase in fan energy use. The Rated Home, however, is required to be simulated with the asdesigned air exchange rate and fan energy use. Consequently, the HERS rules effectively penalize a Rated Home for having mechanical ventilation. In contrast, the 2012 IECC requires mechanical ventilation in all homes and, thus, imposes no penalty on a proposed design. This analysis quantifies the ventilation penalty in the HERS Index to inform the selection of Corresponding HERS Index values.

\subsubsection{Thermostat Set Points}

The IECC and HERS rule sets specify different thermostat setpoints. The IECC specifies heating and cooling setpoints of $72^{\circ} \mathrm{F}$ and $75^{\circ} \mathrm{F}$, respectively, while the HERS rules specify $68^{\circ} \mathrm{F}$ and $78^{\circ} \mathrm{F}$.

The IECC's setpoints will result in higher calculated heating and cooling loads and may result in different relative magnitudes of heating, cooling, water-heating, and other building loads between the two metrics. This analysis evaluates how the setpoint differences impact Corresponding HERS Index values.

\subsubsection{Thermostat Setbacks}

The HERS methodology gives performance credit for the presence of a programmable thermostat in the Rated Home. Such homes are required to be analyzed with a $2^{\circ} \mathrm{F}$ setback from 11 p.m. to 6 a.m. for heating and from 9 a.m. to 3 p.m. for cooling. The IECC performance path does not give credit for the use of a programmable thermostat. Because new homes are likely to have thermostats with automatic setback capabilities, this difference between the two metrics will systematically over-credit most homes. This analysis quantifies that overage to inform the selection of appropriate Corresponding HERS Index values.

\subsection{Other Rule Set Differences}

Several other differences between the HERS and IECC rule sets are expected to potentially result in significant differences in how HERS Index values relate to the IECC Compliance Ratio. Some of these have been evaluated by others and/or there are precedents for how they have been handled, for example, in beyond-code programs. Others may require future work. This analysis has not evaluated these differences. 


\subsubsection{House Size}

Although the two metrics do not treat house size differently, there are physical and practical reasons why the Corresponding HERS Index might be expected to vary with house size. The surface-to-volume ratio of a home impacts its weather sensitivity, the relative magnitudes of heating and cooling loads, the relative importance of internal gains, etc. House size has been evaluated extensively by the Energy Star Homes program. Observing that the HERS Index for a larger home is typically lower than that of a similarly configured but smaller home, the U.S. Environmental Protection Agency (EPA) sought an adjustment factor to lower the qualifying HERS Index value for its Energy Star qualification program. As shown below, the resulting Size Adjustment Factor (SAF) is a function of the conditioned floor area (CFA) of a Rated Home compared to that of a program-defined benchmark home (EPA 2012):

$$
S A F=\left(\frac{C F A_{\text {benchmark home }}}{\text { CFA } A_{\text {rated home }}}\right)^{0.25}
$$

Note that the CFA of the EPA benchmark home varies with the number of bedrooms, and the SAF is constrained to be less than or equal to 1.0. The scaling factor of 0.25 in the equation was chosen as a compromise approximately halfway between making no size adjustment at all, and adjusting sufficiently to ensure a constant carbon footprint regardless of house size (EPA 2009). In that sense, the EPA equation is based on a mixture of technical and policy considerations. Were a similar adjustment applied in a HERS Index-based compliance path, larger homes would be required to achieve lower HERS Index scores. For the present analysis, the EPA benchmark home would correspond to the $2400-\mathrm{ft}^{2}$ prototype used here, and the rated home would correspond to any home seeking compliance via a HERS Indexbased compliance path. The resulting adjustment, if it were based directly on the EPA equation, is shown in Figure 2.1.

Although additional work is needed to determine if the EPA equation provides equitable adjustment compared to the IECC Compliance Ratio, Figure 2.1 provides a rough illustration of the impact of house size. In this hypothetical example, a $6000-\mathrm{ft}^{2}$ home would have a Corresponding HERS Index value that is approximately 80 percent of the Corresponding HERS Index of a $2400-\mathrm{ft}^{2}$ home.

Fairey (2009) conducted a brief evaluation of house size but did not vary size and number of bedrooms independently, so the results are less easily applied to the present analysis. 


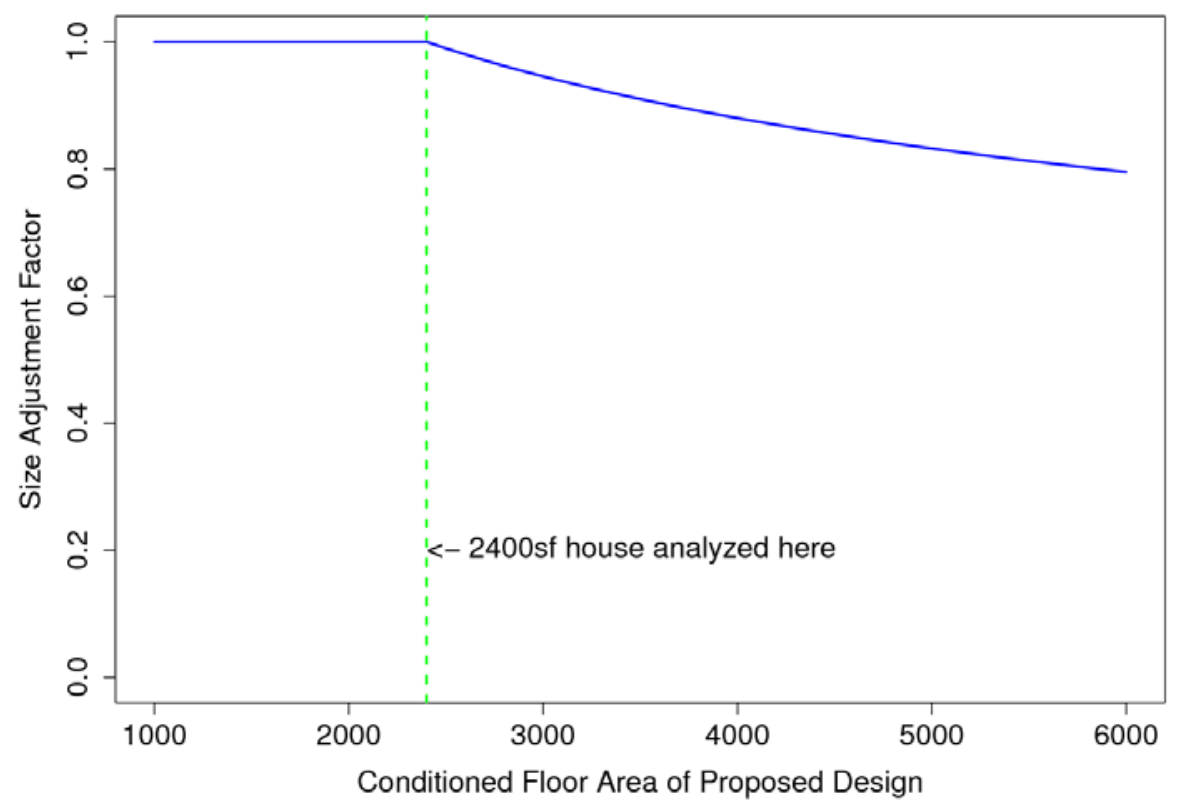

Figure 2.1. Energy Star SAF Applied to Corresponding HERS Index Values with a $2400-\mathrm{ft}^{2}$ Baseline

\subsubsection{Internal Loads}

The IECC performance path specifies heat gain from internal loads as a total daily value that varies with the CFA and number of bedrooms. This value does not depend on the fuel type or location of the home. Internal gains are required to be the same for both the standard reference and the proposed design, and no credit is given for energy-efficient appliances. However, the DOE methodology (Taylor et al. 2012) accounts for energy savings and reduction in internal gains due to the use of high-efficacy (i.e., 75percent efficient) lighting, and the same approach has been used for this analysis.

The HERS methodology splits internal gains by appliances, lighting, and occupants, and specifies a procedure for calculating the reduction in internal gains when energy-efficient appliances are used.

These differences, although small and unlikely to have major impact, potentially impact the metrics in two ways. First, because the HERS standards credit energy-efficient appliances, their use as an alternative compliance path could result in less efficient building envelopes unless the Corresponding HERS Index values are designed to account for this possibility. Second, differences in the overall level of internal gains could impact the relative magnitudes of heating, cooling, and water heating compared to the overall magnitude of the energy performance of the baseline home for either metric. Others have evaluated the impacts of internal gains (Fairey et al. 2006) without reaching solid conclusions. Because the overall magnitude of this effect is expected to be small, it has not been analyzed here.

\subsubsection{Window Area}

The IECC SRD is required to have a 15-percent window to floor area ratio (or smaller if the proposed design has smaller window area), whereas the HERS Reference Home has an 18-percent window to floor ratio. The 15-percent baseline in the IECC is closer to typical values identified in surveys and studies (Lucas 2009), so the HERS value of 18 percent might be considered less stringent from a codes perspective. Also, the IECC gives no credit for window area less than its 
15-percent cutoff, whereas the HERS standards do give credit below the 18-percent value, which further suggests a lower stringency for the HERS standards for many homes. These differences in the treatment of window-area percentage are potentially significant and would require additional analysis to properly account for them in Corresponding HERS Index values. The present analysis does not evaluate windowarea differences.

\subsubsection{Equipment Type and Efficiency}

The IECC SRD is required to have the same equipment efficiencies as the proposed design, thus giving no credit for energy savings due to high-efficiency equipment. The HERS Reference Home is required to comply with the federal minimum efficiency requirements, and the Rated Home is modeled with the actual system efficiencies. Thus, the HERS Index does give credit for high-efficiency equipment, which can be a significant difference from the IECC rule set. If the two metrics were offered side by side in the IECC, the Corresponding HERS Index values would need to account for the differences, and a more thorough analysis of the differences would likely be needed. However, if a HERS-based compliance path were added to the IECC, it is as least somewhat likely that the existing performance path would be modified to also allow tradeoff credit for high-efficiency equipment, which would significantly lessen the potential difference between the two metrics. In either case, this analysis does not evaluate equipment efficiency differences.

The HERS Index metric is defined such that there is a single Index scale for all equipment/fuel types. EPA (2011) evaluated differences in the HERS Index owing to fuel type and found minimal (one-point) differences in warmer climate zones and two- to three-point differences in colder zones. Fairey (2009) found larger differences. Both studies compared a gas furnace with an electric heat pump, and did not evaluate an electric furnace, which might be expected to exhibit greater differences. Additional work would be required to determine how the relationship between the HERS Index and IECC Compliance Ratio varies between fuel types and how that might be accommodated in a compliance path.

\subsubsection{Building Type}

Differences between single-family and multifamily homes can in many ways be considered a combination of differences already discussed — building size, internal gains, equipment type, and perhaps window area. There are other nuanced differences, but it is expected that building type differences are predominantly an aggregation of the other major effects. This analysis does not evaluate building type differences.

\subsection{Metric Differences}

The IECC performance path and the HERS standards quantify energy performance with different metrics. Although both are correlated with the energy consumption in a home, the quantities compared are different. The manner in which the computed metrics are compared between a baseline and a proposed or Rated Home also differ.

\subsubsection{HERS Index}

The HERS Index is a relative measure of energy efficiency performance, with a scale ranging from zero to (theoretically) infinity. A HERS Index score of zero would represent a net-zero energy home. 
A HERS Index score of 100 is defined to represent the "American Standard Home," which is approximately a 2006 IECC-compliant home. A HERS Index score greater than 100 implies the home is less efficient than the 2006 IECC standard home, while a score less than 100 indicates a more efficient home. Each one-point decrease in the HERS Index corresponds approximately to a 1-percent reduction in energy consumption compared to the 2006 IECC-based HERS Reference Home. Thus, for example, a home with a HERS Index score of 90 is expected to be 10-percent more efficient than if it just complied with the 2006 IECC.

The HERS Index score is the ratio of a Rated Home's performance to that of the HERS Reference Home, where performance is defined by nMEUL. The nMEUL is based on simulated building loads (as opposed to energy consumption or energy cost). The indicated normalization is designed to allow homes to use the same HERS Index scale regardless of the fuel type(s) used for space conditioning and water heating. The nMEUL incorporates whole-building loads, so all major end uses are considered.

\subsubsection{IECC Compliance Ratio}

The IECC performance path bases compliance on a comparison of energy costs (or source energy) between the SRD and the proposed design. The proposed design is required to have an annual energy cost equal to or less than that of the SRD. Only heating, cooling, and water-heating end uses are considered for the energy cost metric comparison. The DOE cost-effectiveness methodology (Taylor et al. 2012) used for this analysis considers lighting energy for this metric as well to facilitate comparisons against older versions of the code that had no high-efficacy lighting requirements. However, the 2012 IECC performance path gives no credit for a higher percentage of high-efficacy lighting.

The IECC performance path acknowledges only a binary result. If the energy cost of the proposed design is equal to or lower than that of the SRD, the home is compliant; otherwise it is not. The code does not concern itself with how much better (or worse) a proposed design might be relative to the SRD. However, to allow quantitative comparisons of the behavior of the HERS Index with that of the IECC performance path, an IECC Compliance Ratio has been defined. The Compliance Ratio is simply the ratio of the energy cost of the proposed design to that of the SRD. Thus, a Compliance Ratio greater than 1.0 indicates noncompliance, and a lower Compliance Ratio represents better-than-standard performance. Note, for the 2012 IECC, the Compliance Ratio is anchored at 1.0, while for the 2006 IECC, the HERS Index is anchored at 100 .

\subsection{Interpreting the Correlation between the HERS Index and the IECC Compliance Ratio}

As a result of the previously described differences between the HERS Index and the 2012 IECC Compliance Ratio, a direct correspondence between the two metrics cannot be expected. Nonetheless, if a HERS-based compliance path were added to the IECC, it would be necessary that the two metrics be sufficiently correlated that the HERS-based path would result in similar energy performance to the IECC performance path. Considering what might be expected if there were "perfect" correlation may aid understanding how the two metrics relate. For the purpose of the present analysis, a perfect correlation would mean that a relative improvement in energy performance on one of the scales would result in the same relative improvement on the other scale. It also is desirable to have a known correspondence that is 
explicable between the anchor points of the two scales (2006 IECC for the HERS Index; 2012 IECC for the IECC Compliance Ratio).

PNNL has estimated the difference in energy performance between the 2006 and 2012 IECCs, on a national average basis, to be 32.8 percent for single-family homes (Lucas et al. 2012). Climate zonespecific averages from the same study range from 25.7 to 38.3 percent. Those results have established a common expectation of about 30-percent improvement can be used to define a point of perfect correspondence between the two scales. The graph in Figure 2.2 illustrates this hypothetical perfect correlation with a dashed red line. Note that a HERS Index score of 70 corresponds to an IECC Compliance Ratio of 1.0, reflecting the approximately 30-percent improvement of the 2012 IECC over the 2006 IECC. Also note that a given percentage change in the HERS Index score corresponds to an identical percentage change in the Compliance Ratio. This line, which can be thought to represent the common expectation of how the two metrics should relate, is shown for reference on all further graphics comparing the HERS Index and Compliance Ratio.

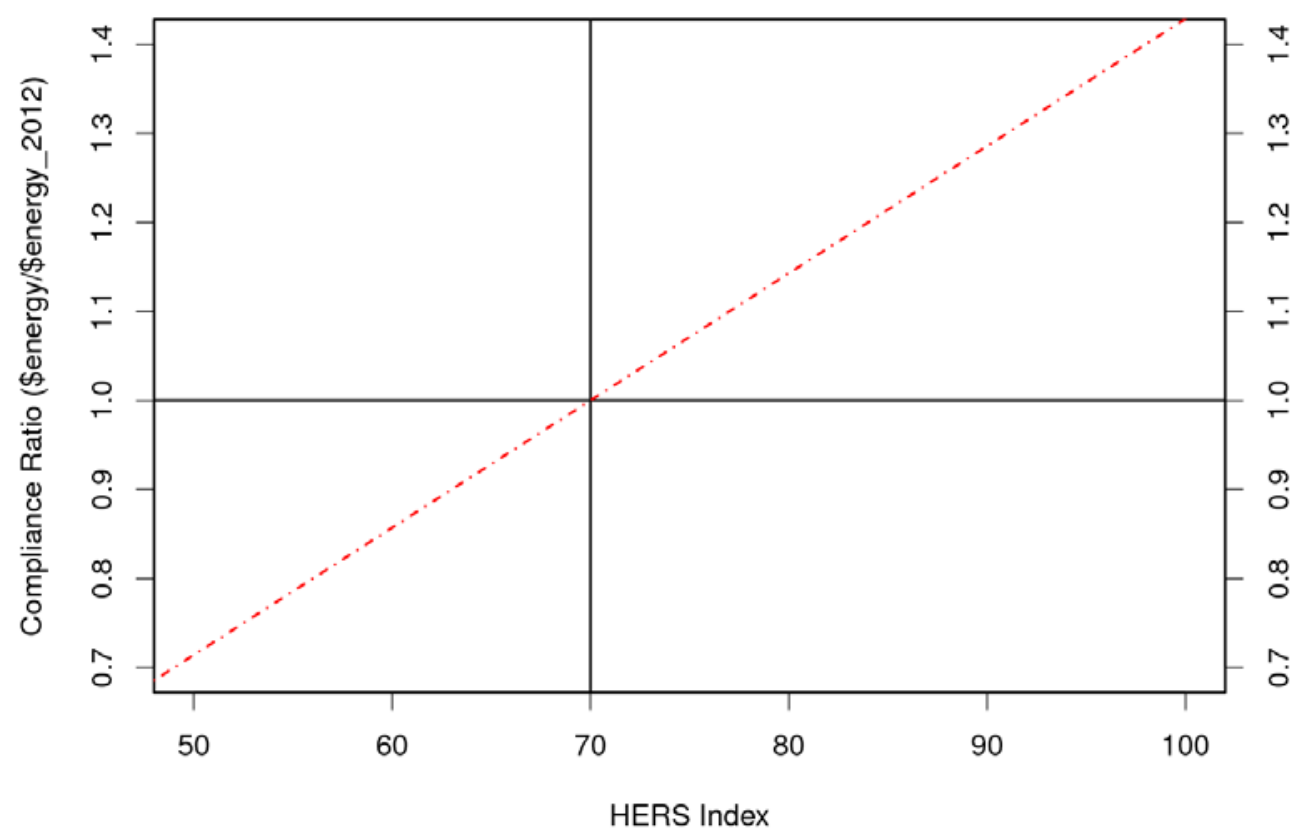

Figure 2.2. Hypothetical Perfect Relationship between the 2012 IECC Compliance Ratio and the HERS Index 


\subsection{Analysis Method}

\subsection{Simulation Tool}

DOE's residential cost-effectiveness methodology (Taylor et al. 2012) establishes EnergyPlus as the primary simulation tool for analysis. EnergyPlus provides for a detailed hour-by-hour (or more frequent) simulation of energy consumption in a home throughout a full year, based on typical weather data for a location. It covers almost all aspects of residential envelopes: heating, ventilation, and air-conditioning (HVAC) equipment and systems; water-heating equipment and systems; and lighting systems.

\subsection{Locations}

Simulations are conducted in one weather location per IECC climate zone, including a separate location for each moisture regime. The locations in Table 3.1 have been selected to represent their respective climate zones (Briggs et al. 2002).

Table 3.1. Climate Locations Used for Analysis

\begin{tabular}{llcl}
\hline \multicolumn{1}{c}{ Location } & State & Climate Zone & Moisture Regime \\
\hline Miami & Florida & 1 & Moist \\
Phoenix & Arizona & 2 & Dry \\
Houston & Texas & 2 & Moist \\
El Paso & Texas & 3 & Dry \\
San Francisco & California & 3 & Marine \\
Memphis & Tennessee & 3 & Moist \\
Albuquerque & New Mexico & 4 & Dry \\
Salem & Oregon & 4 & Marine \\
Baltimore & Maryland & 4 & moist \\
Boise & Idaho & 5 & Dry \\
Chicago & Illinois & 5 & Moist \\
Helena & Montana & 6 & Dry \\
Burlington & Vermont & 6 & Moist \\
Duluth & Minnesota & 7 & None defined \\
Fairbanks & Alaska & 8 & None defined \\
\hline
\end{tabular}

\subsection{Prototype Model Description}

The single-family prototype defined in the DOE cost-effectiveness methodology (Taylor et al. 2012) has been used for this analysis. The single-family prototype is configured as a two-story rectangular building with $2400 \mathrm{ft}^{2}$ of CFA. This prototype has been evaluated with one foundation type (vented crawlspace) and one heating system type (gas furnace). 


\subsection{Assumptions for Evaluated Homes}

To compare how the two energy-performance metrics vary with changes in the energy efficiency of a home, a suite of 33 prototype configurations was simulated in each climate location. These configurations cover the major building components within the scope of the 2012 IECC and include both IECC-compliant and noncompliant homes. The 33 configurations include one that minimally complies with the 2012 IECC prescriptive requirements and 32 configurations either better or worse in terms of overall energy performance. The 32 alternative configurations involve varying opaque envelope conductance, fenestration U-factors, envelope air leakage rates, and mechanical equipment efficiencies. Table 3.2 shows the ranges of envelope factors used to develop the 33 configurations.

Each of the 33 configurations is analyzed in each of the 15 climate locations. Both a HERS Index score and a 2012 IECC Compliance Ratio are calculated for each of the 495 (33 configurations $\times$ 15 climate locations) cases. Figure 3.1 shows the results, with the Compliance Ratio plotted against the HERS Index for all cases. Note that there is a horizontal grid line (green) where Compliance Ratio equals 1.0; this is the boundary between cases that comply with the code and those that do not. The dashed red line is the theoretical line of perfect correlation discussed in Section 2.6. The solid black line drawn through the scatter plot is a fitted curve based on simple linear regression. The solid black vertical line shows the point at which the regression line crosses the compliance boundary axis, showing that a HERS Index score of 69.6 will comply with the code on average. ${ }^{1}$

Figure 3.1 shows that, taking all locations together, the HERS Index is reasonably correlated with Compliance Ratio, although not perfectly so. The average Corresponding HERS Index is 67.4, which is close to the common expectation of 70 based on the respective code baselines of the two metrics (2006 IECC for the HERS Index; 2012 IECC for the Compliance Ratio). The slope of the regression line differs slightly from the line of perfect correlation, indicating a slight difference in relative performance as indicated by the two metrics. Finally, there is considerable scatter around the average Corresponding HERS Index of 67.4, with values ranging from about 60 to slightly over 75 . This scatter is not unexpected, especially with all climates included in the same graph.

\footnotetext{
${ }^{1}$ The HERS standards require that HERS Index values be integers. One decimal place has been retained in these calculations to facilitate clearer visualization of the differences under analysis.
} 
Table 3.2. Ranges of Component Characteristics Used for 33 Prototype Configurations

\begin{tabular}{|c|c|c|c|c|c|c|c|c|c|c|c|c|}
\hline \multirow[b]{2}{*}{ Location } & \multicolumn{3}{|c|}{ Climate } & \multirow[b]{2}{*}{$\begin{array}{c}\text { Wall } \\
\text { R-Value } \\
\text { (Batt) }\end{array}$} & \multicolumn{6}{|c|}{33 Test Cases } & \multirow[b]{2}{*}{$\begin{array}{c}\text { Heating } \\
\text { AFUE }\end{array}$} & \multirow[b]{2}{*}{$\begin{array}{c}\text { Water } \\
\text { Heater EF }\end{array}$} \\
\hline & & $\begin{array}{l}\text { one and } \\
\text { Ioisture } \\
\text { Regime }\end{array}$ & $\begin{array}{c}\text { Ceiling } \\
\text { R-Value }\end{array}$ & & $\begin{array}{c}\text { Wall } \\
\text { R-Value } \\
\text { (Continuous) }\end{array}$ & $\begin{array}{c}\text { Floor } \\
\text { R-Value }\end{array}$ & $\begin{array}{l}\text { Window } \\
\text { U-Factor }\end{array}$ & $\begin{array}{l}\text { Window } \\
\text { SHGC }\end{array}$ & $\begin{array}{c}\text { Envelope } \\
\text { Leakage } \\
\text { (ACH50) }\end{array}$ & $\begin{array}{c}\text { Cooling } \\
\text { SEER }\end{array}$ & & \\
\hline Miami & 1 & Moist & $19-49$ & $13-19$ & $0-5$ & $13-19$ & $1.20-0.20$ & $0.45-0.15$ & $7-3$ & $13-17$ & $78-90$ & $0.59-0.67$ \\
\hline Houston & 2 & Moist & $19-60$ & $13-19$ & $0-5$ & $13-19$ & $0.75-0.20$ & $0.45-0.15$ & $7-3$ & $13-17$ & $78-90$ & $0.59-0.67$ \\
\hline Phoenix & 2 & Dry & $19-60$ & 13-19 & $0-5$ & $13-19$ & $0.75-0.20$ & $0.45-0.15$ & $7-3$ & $13-17$ & $78-90$ & $0.59-0.67$ \\
\hline El Paso & 3 & Dry & $19-60$ & $13-21$ & $0-10$ & $13-30$ & $0.75-0.20$ & $0.45-0.15$ & $7-1.7$ & $13-17$ & $78-90$ & $0.59-0.67$ \\
\hline Memphis & 3 & Moist & $19-60$ & $13-21$ & $0-10$ & $13-30$ & $0.75-0.20$ & $0.45-0.15$ & $7-1.7$ & $13-17$ & 78-90 & $0.59-0.67$ \\
\hline San Francisco & 3 & Marine & $19-60$ & $13-21$ & $0-10$ & $13-30$ & $0.75-0.20$ & $0.45-0.15$ & $7-1.7$ & $13-17$ & 78-90 & $0.59-0.67$ \\
\hline Albuquerque & 4 & Dry & $19-60$ & $13-21$ & $0-10$ & $13-30$ & $0.75-0.20$ & $0.60-0.35$ & $7-1.7$ & $13-17$ & $78-90$ & $0.59-0.67$ \\
\hline Baltimore & 4 & Moist & $19-60$ & $13-21$ & $0-10$ & $13-30$ & $0.75-0.20$ & $0.60-0.35$ & $7-1.7$ & $13-17$ & $78-90$ & $0.59-0.67$ \\
\hline Salem & 4 & Marine & $19-60$ & $13-21$ & $0-10$ & $13-30$ & $0.65-0.30$ & 0.40 & $7-1.7$ & $13-15$ & $78-96$ & $0.59-0.67$ \\
\hline Boise & 5 & Dry & $19-60$ & $13-21$ & $0-10$ & $13-30$ & $0.65-0.30$ & 0.40 & $7-1.7$ & $13-15$ & $78-96$ & $0.59-0.67$ \\
\hline Chicago & 5 & Moist & $19-60$ & $13-21$ & $0-10$ & $13-30$ & $0.65-0.30$ & 0.40 & $7-1.7$ & $13-15$ & $78-96$ & $0.59-0.67$ \\
\hline Burlington & 6 & Moist & 19-60 & $13-21$ & $0-10$ & $13-30$ & $0.65-0.30$ & 0.40 & $7-1.7$ & 13-15 & 78-96 & $0.59-0.67$ \\
\hline Helena & 6 & Dry & $19-60$ & $13-21$ & 0-10 & $13-30$ & $0.65-0.30$ & 0.40 & $7-1.7$ & 13-15 & 78-96 & $0.59-0.67$ \\
\hline Duluth & 7 & None & $19-60$ & $13-21$ & $0-10$ & $13-30$ & $0.65-0.30$ & 0.40 & $7-1.7$ & $13-15$ & 78-96 & $0.59-0.67$ \\
\hline Fairbanks & 8 & None & $19-60$ & $13-21$ & $0-10$ & $13-49$ & $0.65-0.30$ & 0.40 & $7-1.7$ & $13-15$ & $78-96$ & $0.59-0.67$ \\
\hline
\end{tabular}




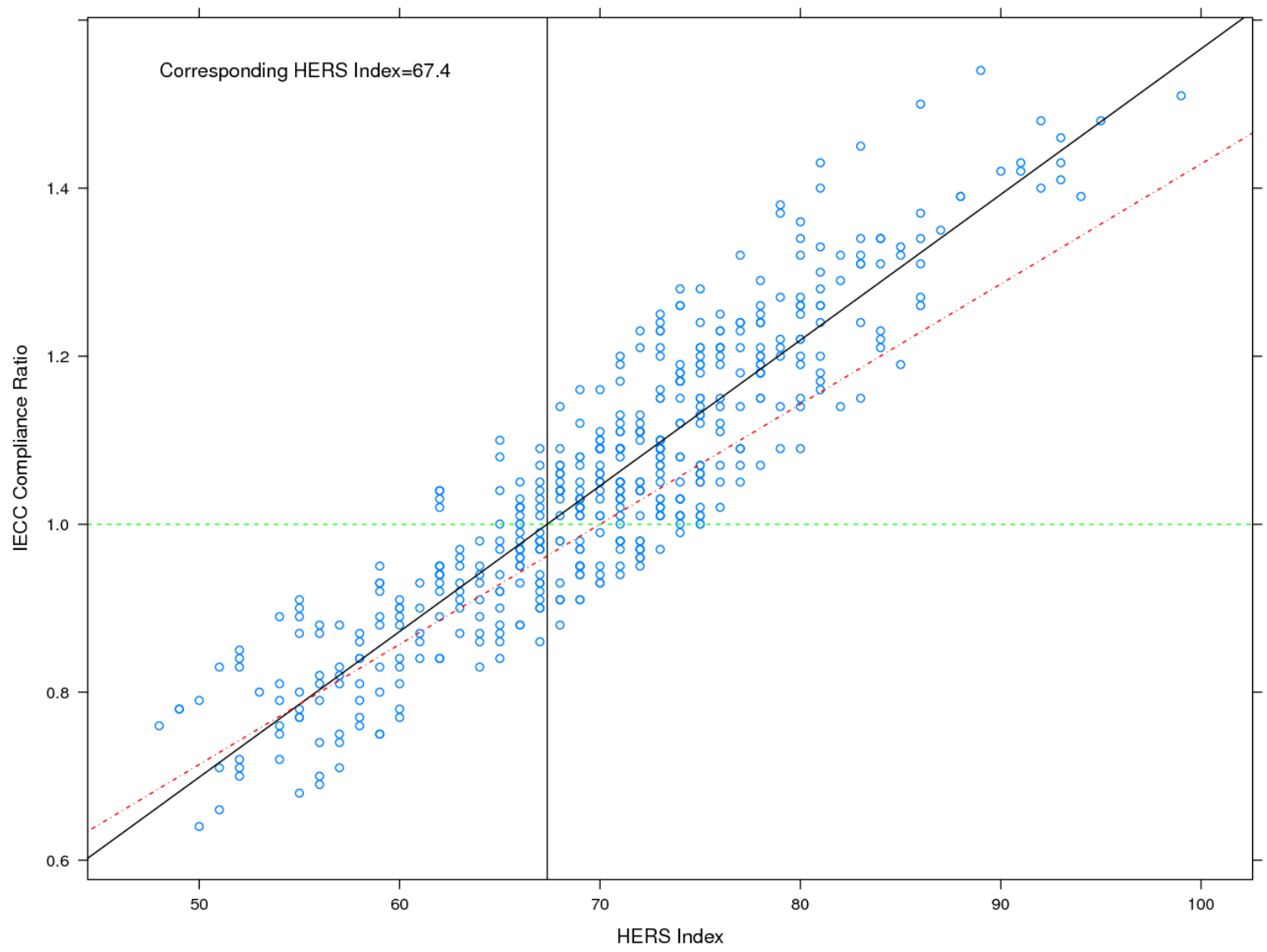

Figure 3.1. 2012 IECC Compliance Ratio versus HERS Index for 33 Test Cases in 15 Locations

Figure 3.2 shows a similar graph for each of the 15 climate locations (which correspond to the unique combinations of zone and moisture regime). Each of the 15 panels is formatted similarly to Figure 3.1, although there are fewer data points (33) in each climate panel. Note that there is substantial variation across both zones and moisture regimes and that the departure from the expected Corresponding HERS Index score of 70 is greater in many individual zones than when all zones are lumped together. Complying scores vary from a high of 73.7 in Zones 1- and 2-moist to a low of 62.0 in Zone 7.

It is notable that the relationship between IECC Compliance Ratio and HERS Index is consistently linear, cleanly represented by a fitted regression line in all climate zones. Although there is some scatter around the fitted curve, there appears to be no systematic departure from linearity or unacceptable variance around the curve in any climate zone, suggesting that the methodology could be simplified by using considerably fewer than 33 house configurations to define the lines of IECC-HERS correspondence. 


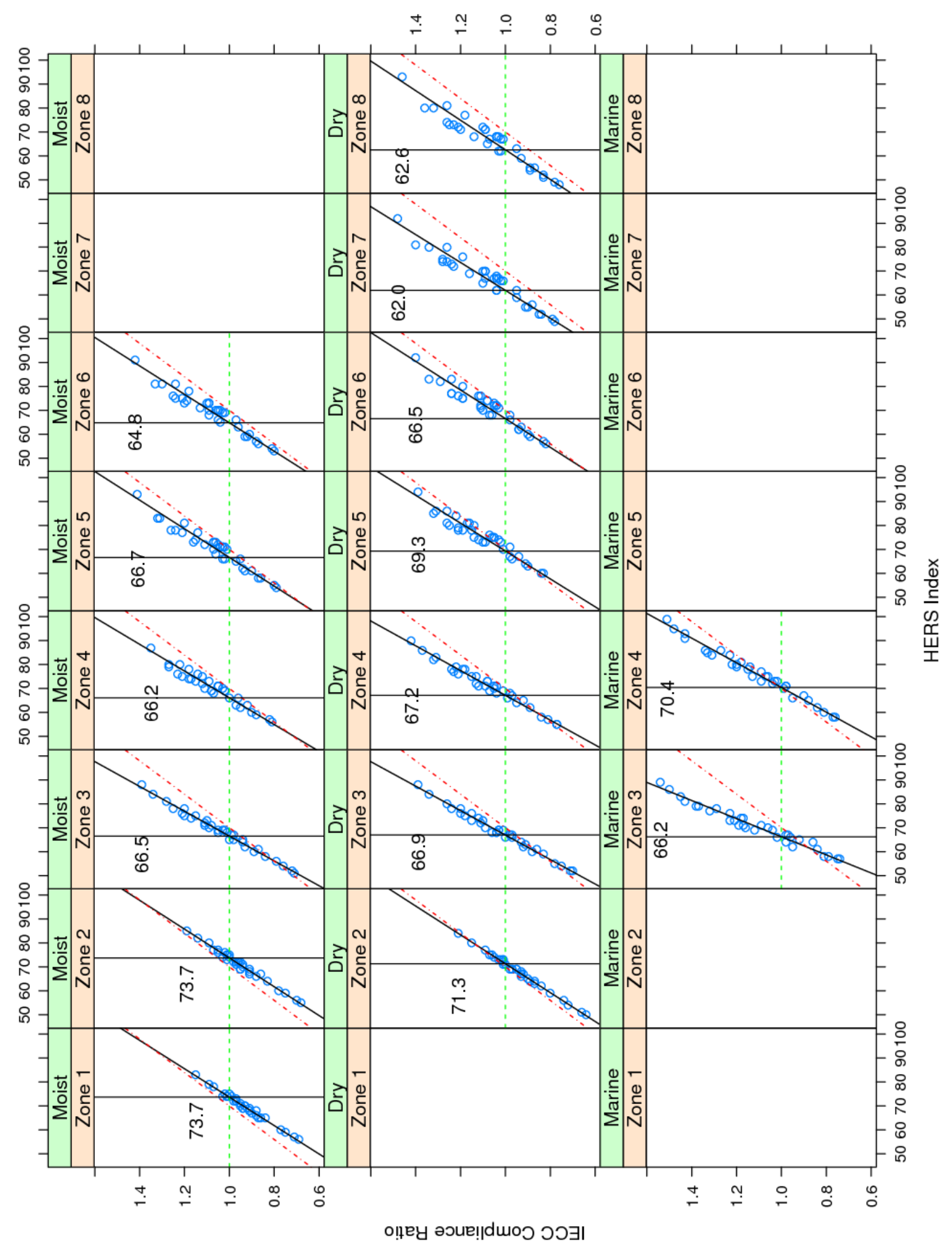

Figure 3.2. 2012 IECC Compliance Ratio versus HERS Index by Climate Zone and Moisture Regime 


\subsection{Rule Set Differences and Parameters Analyzed}

The departures from common expectations result from many differences between the definitions and simulation rules of the two metrics. The three major differences that are expected to cause departure from the line of perfect correlation are briefly described below:

1. The HERS Index assumes no mechanical ventilation in its baseline, while the IECC Compliance Ratio does. Because the 2012 IECC requires mechanical ventilation in all homes, every HERS Index score of a compliant home will be penalized (HERS Index score increased) for the presence of mechanical ventilation.

2. The HERS Index and the IECC Compliance Ratio are based on different baseline thermostat setpoint assumptions.

3. The HERS rules give credit for the presence of an automatic setback thermostat, while the IECC Compliance Ratio does not.

Each of these differences is discussed in more detail in the following sections.

\subsubsection{Mechanical Ventilation}

The HERS Reference Home does not account for increased air exchange over natural infiltration when mechanical ventilation is used in the Rated Home. Mechanical ventilation is a mandatory requirement of the 2012 IECC, and the SRD accounts for the corresponding increase in air exchange rate. Figure 3.3 shows the energy use for the HERS Reference Home both with and without mechanical ventilation. The ventilation increases the heating and cooling energy for the HERS Reference Home and can result in a worse (i.e., higher) HERS Index for the Rated Home as compared to the standard HERS baseline. The impact of this difference on the correlation between the HERS Index and the IECC Compliance Ratio can be evaluated by recalculating the HERS Index with a modified HERS baseline that includes mechanical ventilation. ${ }^{1}$

\footnotetext{
${ }^{1}$ Alternatively, the ventilation assumptions of the IECC performance path could have been modified. Modifying the HERS assumption to evaluate this phenomenon was an arbitrary choice.
} 


\section{Impact of Mechanical Ventilation on the HERS Baseline}

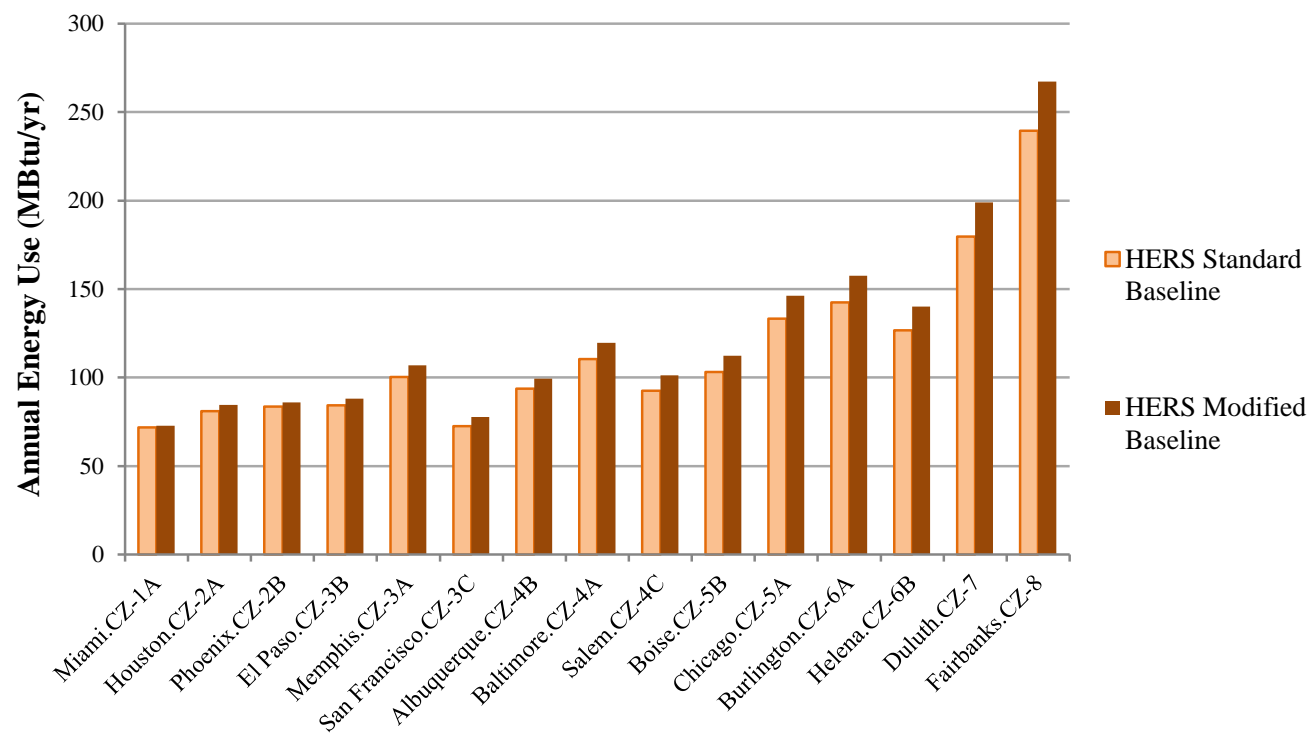

Figure 3.3. Energy Impact of Mechanical Ventilation on the HERS Reference Home

To illustrate and quantify the mechanical ventilation effect, correlation plots that include the ventilation-modified HERS baseline were produced for comparison with the standard HERS baseline plots of Figure 3.2. These results are shown in Figure 3.4 . Note that, for some zones, the Corresponding HERS Index differs substantially from that based on the standard HERS ventilation assumption as shown in Table 3.3. The differences in Corresponding HERS Index range from less than two to almost six.

The differences due to mechanical ventilation are incidental to determining valid Corresponding HERS Index values. If the complying values are chosen based on standard HERS rules, there is no problem as long as homes complying via a HERS-based compliance path include mechanical ventilation as required by the 2012 IECC. These differences are highlighted, however, as a warning to any state or jurisdiction that either adopts the code with an amendment eliminating the ventilation requirement or fails to enforce the ventilation requirement. Either would result in builders having a compliance bypass up to five points on the HERS Index with which to trade away other efficiency features of the home. Beyond this warning, the ventilation-modified Corresponding HERS Index values are not used further in this report. 
Table 3.3. Comparison of Corresponding HERS Index Values with and without Mechanical Ventilation in the HERS Reference Home

\begin{tabular}{cccc}
\hline & & \multicolumn{2}{c}{ Corresponding HERS Index } \\
\cline { 3 - 4 } $\begin{array}{c}\text { Climate Zone and } \\
\text { Moisture Regime }\end{array}$ & $\begin{array}{c}\text { Standard HERS } \\
\text { Baseline }\end{array}$ & $\begin{array}{c}\text { Modified HERS Baseline } \\
\text { Including Mechanical } \\
\text { Ventilation }\end{array}$ \\
\hline 1 & Moist & 73.7 & 72.4 \\
\hline 2 & Moist & 73.7 & 71.4 \\
\hline 2 & Dry & 71.3 & 69.7 \\
\hline 3 & Moist & 66.5 & 63.4 \\
\hline 3 & Dry & 66.9 & 65.4 \\
\hline 3 & Marine & 66.2 & 63.4 \\
\hline 4 & Moist & 66.2 & 62.5 \\
\hline 4 & Dry & 67.2 & 65.2 \\
\hline 4 & Marine & 70.4 & 66.9 \\
\hline 5 & Moist & 66.7 & 62.2 \\
\hline 5 & Dry & 69.3 & 65.9 \\
\hline 6 & Moist & 64.8 & 60.0 \\
\hline 6 & Dry & 66.5 & 61.9 \\
\hline 7 & None & 62.0 & 57.0 \\
\hline 8 & None & 62.6 & 57.0 \\
\hline
\end{tabular}




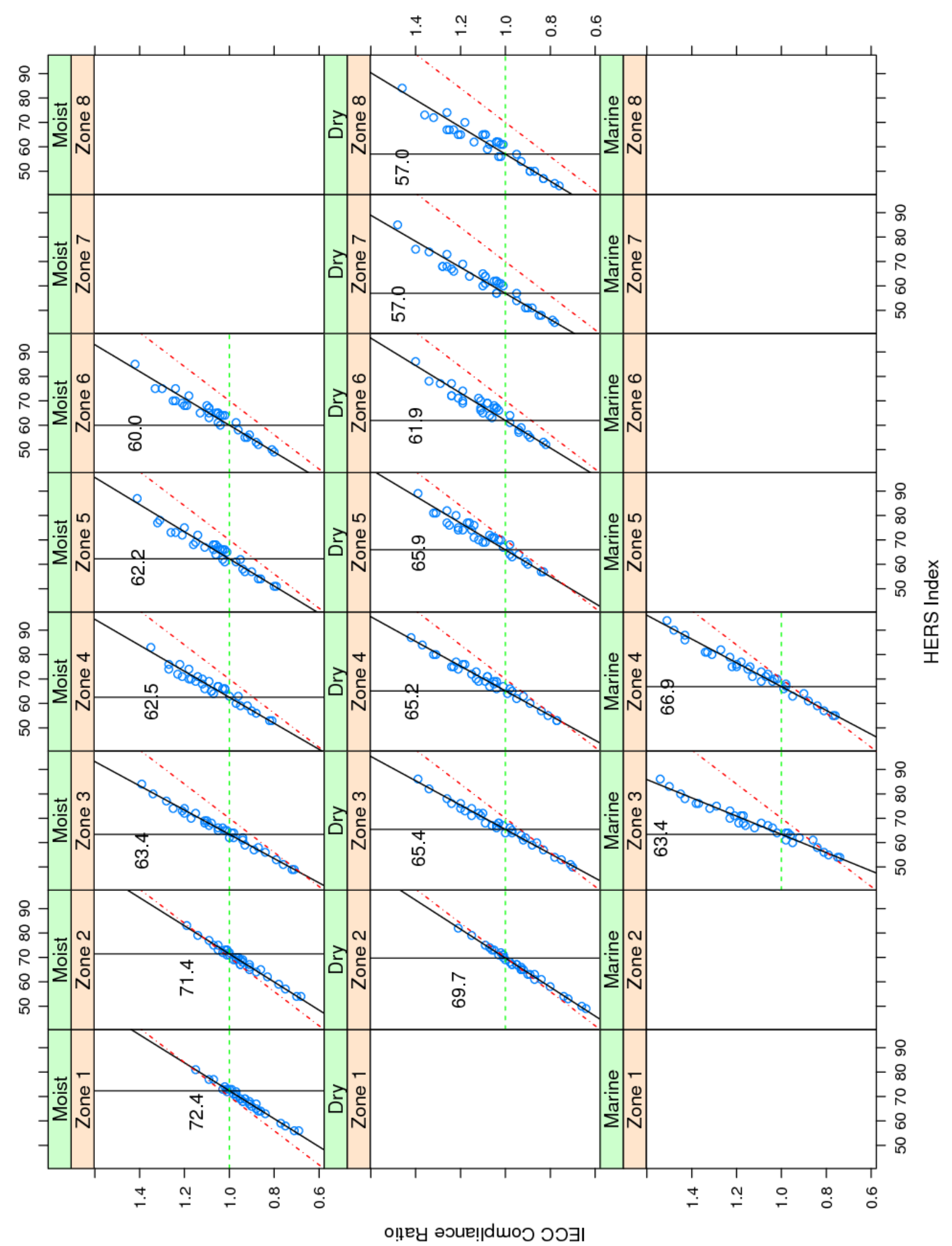

Figure 3.4. 2012 IECC Compliance Ratio versus Ventilation-Modified HERS Index by Climate Zone and Moisture Regime 


\subsubsection{Thermostat Setpoints}

The HERS rule set specifies indoor temperature setpoints of $68^{\circ} \mathrm{F}$ for heating and $78^{\circ} \mathrm{F}$ for cooling, while the 2012 IECC specifies $72^{\circ} \mathrm{F}$ and $75^{\circ} \mathrm{F}$, respectively. The difference in setpoints results in greater heating and cooling loads for homes analyzed for the IECC than for a HERS Index, all else being equal. The setpoint difference affects both the SRD and the proposed design, so it is not immediately obvious how it might affect the ratio between the two. The impact of this difference on the correlation between the HERS Index and the IECC Compliance Ratio was evaluated by modifying the HERS Reference Home to use IECC-based thermostat setpoints. ${ }^{1}$ Figure 3.5 shows the energy use of a HERS Rated Home, complying with the 2012 IECC, when simulated with both the HERS standard $68^{\circ} \mathrm{F} / 78^{\circ} \mathrm{F}$ setpoints and the IECC standard $72^{\circ} \mathrm{F} / 75^{\circ} \mathrm{F}$ setpoints.

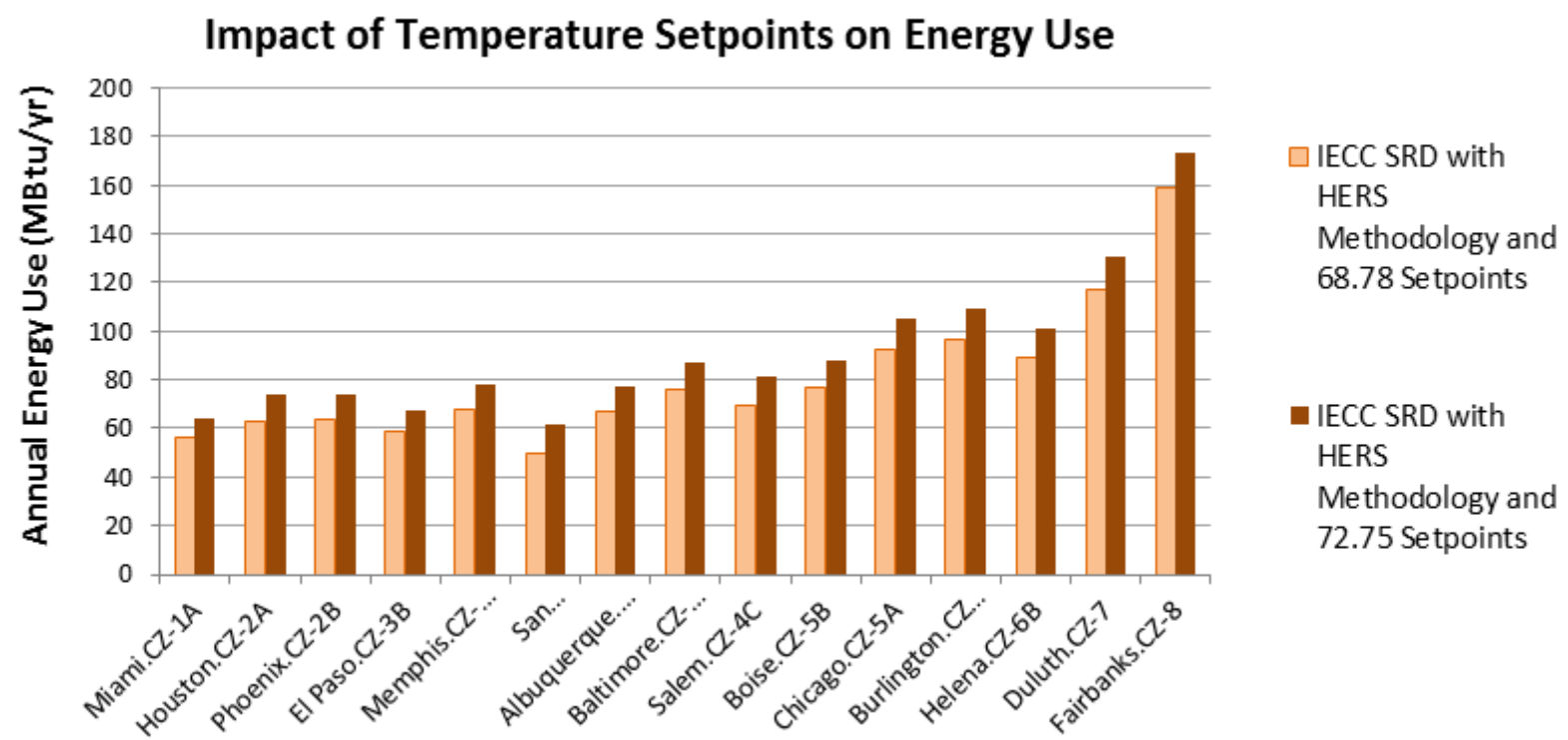

Figure 3.5. Variation in Energy Use Due to Temperature Set Points

As Figure 3.5 indicates, temperature setpoints affect the energy use of the Rated Home noticeably. To illustrate and quantify the thermostat setpoint effect, correlation plots showing the HERS Index calculated with both the HERS standard setpoints and with the IECC standard setpoints have been produced.

Figure 3.6 shows how the Compliance Ratio and HERS Index relate if the HERS rule set is modified to use IECC setpoints. Note that while the Corresponding HERS Index still varies by zone and moisture regime, its values are modestly lower than the corresponding values in Figure 3.2. Table 3.4 summarizes these differences, which are rarely more than a single point on the HERS Index scale. The worst case is a 4.2-point difference in Zone 3-Marine, a zone represented by San Francisco, which has very small heating and cooling loads and, hence, is more sensitive, in relative terms, to changes in setpoints. The setpointmodified HERS results suggest that the setpoint differences are at most a minor consideration in selecting

\footnotetext{
${ }^{1}$ Alternatively, the setpoints in the IECC performance path could have been modified. Modifying the HERS setpoints to evaluate this phenomenon was an arbitrary choice.
} 
Corresponding HERS Index values. The setpoint-modified HERS results are not used further in this report.

Table 3.4. Comparison of Corresponding HERS Index Values with and without Adjustment to Thermostat Setpoints in the HERS Reference Home

\begin{tabular}{|c|c|c|c|}
\hline & & \multicolumn{2}{|c|}{ Corresponding HERS Index } \\
\hline \multicolumn{2}{|c|}{$\begin{array}{l}\text { Climate Zone and } \\
\text { Moisture Regime }\end{array}$} & $\begin{array}{c}\text { Standard HERS } \\
\text { Rule Set }\end{array}$ & $\begin{array}{l}\text { Modified HERS Rule Set } \\
\text { with IECC-Defined } \\
\text { Setpoints }\end{array}$ \\
\hline 1 & Moist & 73.7 & 73.5 \\
\hline 2 & Moist & 73.7 & 73.6 \\
\hline 2 & Dry & 71.3 & 71.5 \\
\hline 3 & Moist & 66.5 & 65.3 \\
\hline 3 & Dry & 66.9 & 65.9 \\
\hline 3 & Marine & 66.2 & 62.0 \\
\hline 4 & Moist & 66.2 & 64.9 \\
\hline 4 & Dry & 67.2 & 66.1 \\
\hline 4 & Marine & 70.4 & 69.2 \\
\hline 5 & Moist & 66.7 & 65.9 \\
\hline 5 & Dry & 69.3 & 68.1 \\
\hline 6 & Moist & 64.8 & 64.0 \\
\hline 6 & Dry & 66.5 & 65.6 \\
\hline 7 & None & 62.0 & 61.6 \\
\hline 8 & None & 62.6 & 62.1 \\
\hline
\end{tabular}




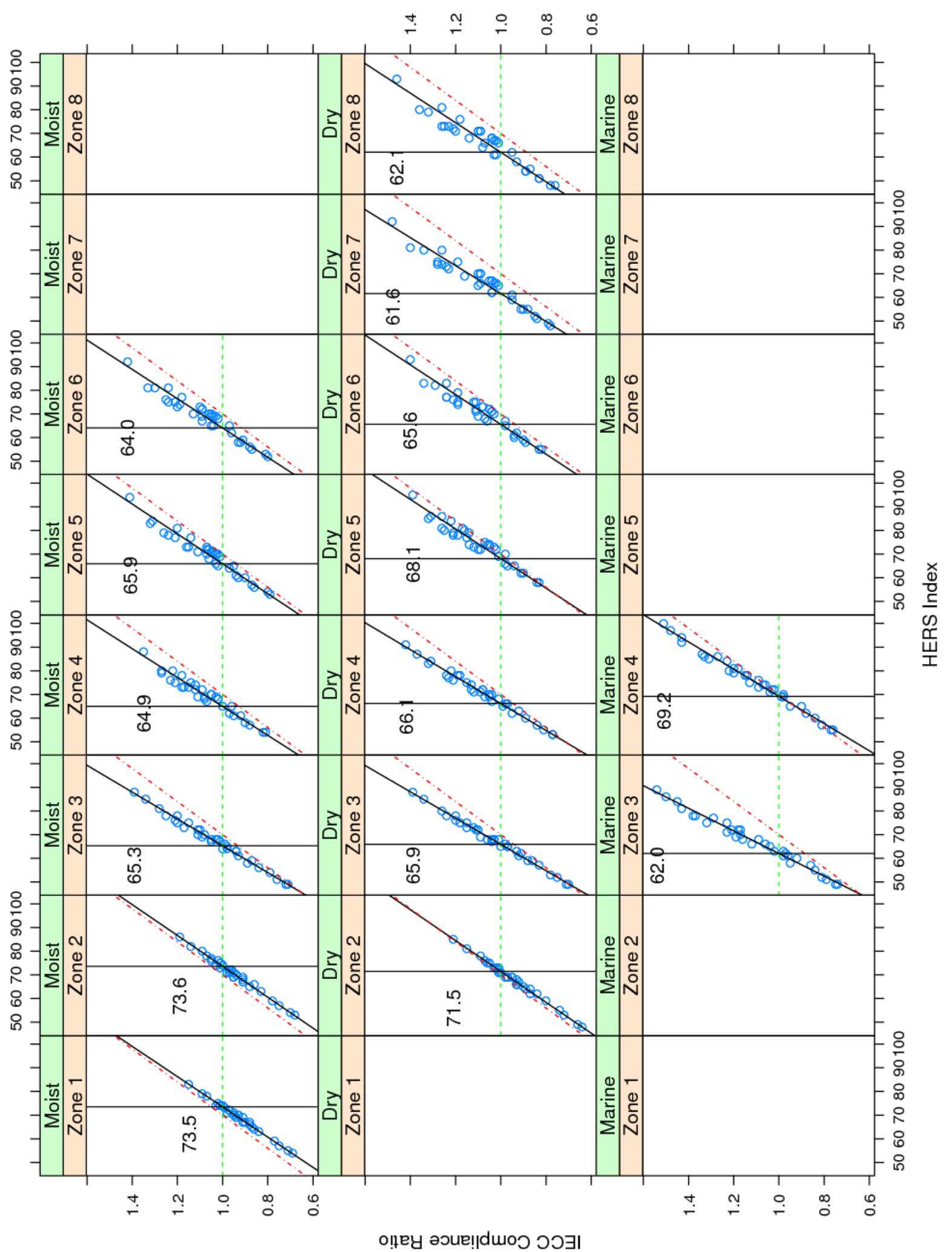

Figure 3.6. 2012 IECC Compliance Ratio versus Setpoint-Modified HERS Index by Climate Zone and Moisture Regime 


\subsubsection{Thermostat Setbacks}

The final difference between the two metrics examined in this report is the thermostat setback. The HERS methodology gives credit for the presence of a programmable thermostat in a Rated Home whereas the IECC rule set does not. Although the credit is based on a setback/setup of only $2^{\circ} \mathrm{F}$, the difference is potentially important in establishing proper code-Corresponding HERS Index values. Figure 3.7 shows the energy use of a HERS Rated Home that is compliant with the IECC 2012 requirements, when simulated with and without thermostat setbacks.

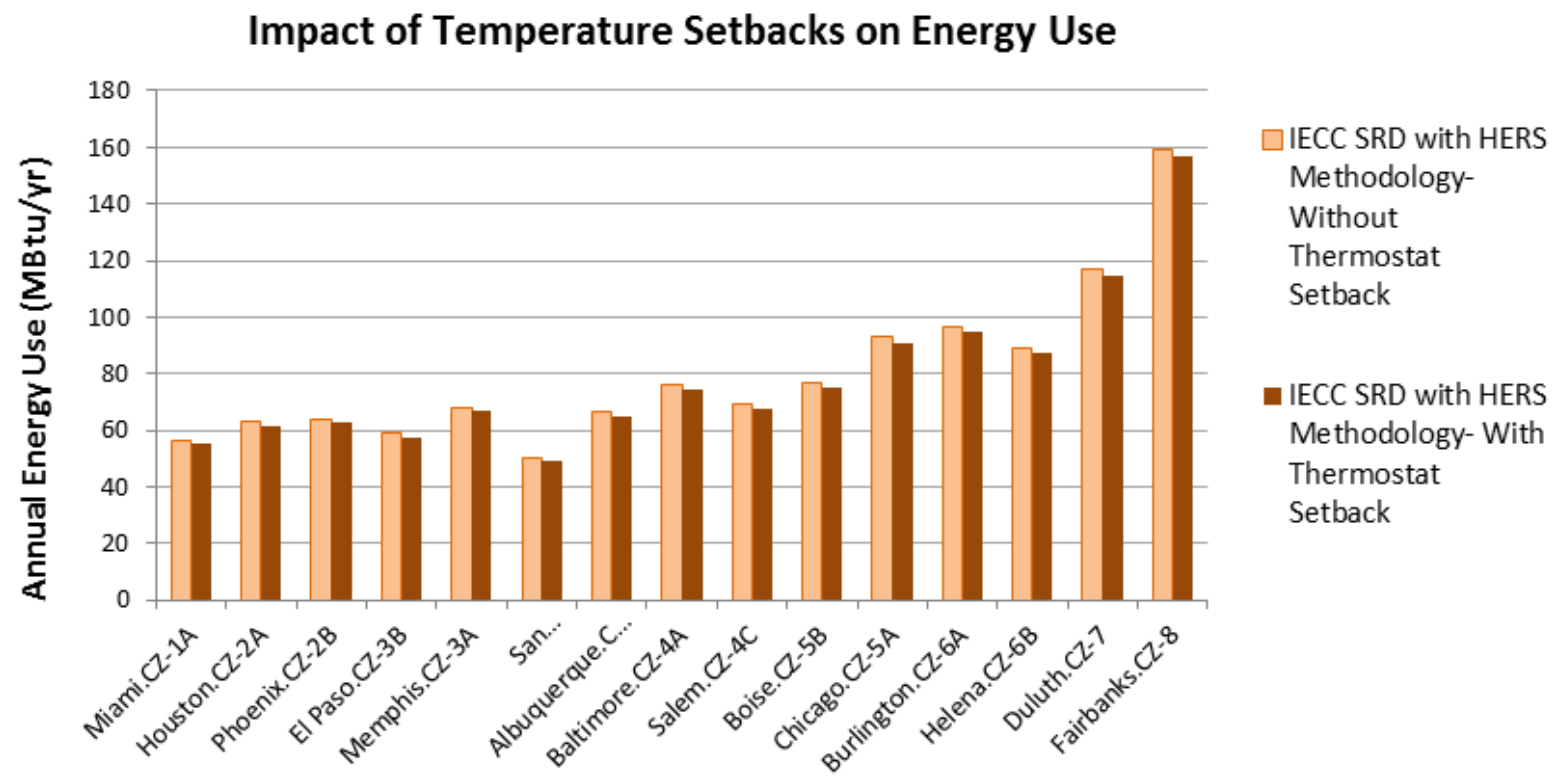

Figure 3.7. Variation in Energy Use Due to Thermostat Setbacks

Because many, if not most, new homes are equipped with automatic setback thermostats, this difference represents a systematic error that would reduce the efficiency of homes complying via a HERS compliance path if it is not accounted for in establishing the Corresponding HERS Index values. Figure 3.8 plots Compliance Ratio versus HERS Index for homes that with an automatic setback thermostat. Table 3.5 summarizes the Corresponding HERS Index values from Figure 3.8 with those from Figure 3.2. The setback results are, as expected, consistently lower by about or two points. Consequently, the Corresponding HERS Index values chosen for a HERS compliance path must be lowered by about two points to account for the expected predominance of automatic setback thermostats in new homes. 
Table 3.5. Comparison of Corresponding HERS Index Values with and without Automatic Setback Thermostats in the HERS Rated Home

\begin{tabular}{|c|c|c|c|}
\hline & & \multicolumn{2}{|c|}{ Corresponding HERS Index } \\
\hline \multicolumn{2}{|c|}{$\begin{array}{l}\text { Climate Zone and } \\
\text { Moisture Regime }\end{array}$} & $\begin{array}{l}\text { No Automatic } \\
\text { Setback } \\
\text { Thermostat }\end{array}$ & $\begin{array}{c}\text { Automatic Setback } \\
\text { Thermostat in Rated Home }\end{array}$ \\
\hline 1 & Moist & 73.7 & 71.7 \\
\hline 2 & Moist & 73.7 & 71.7 \\
\hline 2 & Dry & 71.3 & 70.0 \\
\hline 3 & Moist & 66.5 & 65.0 \\
\hline 3 & Dry & 66.9 & 65.4 \\
\hline 3 & Marine & 66.2 & 64.5 \\
\hline 4 & Moist & 66.2 & 64.7 \\
\hline 4 & Dry & 67.2 & 65.4 \\
\hline 4 & Marine & 70.4 & 68.9 \\
\hline 5 & Moist & 66.7 & 65.2 \\
\hline 5 & Dry & 69.3 & 68.0 \\
\hline 6 & Moist & 64.8 & 63.4 \\
\hline 6 & Dry & 66.5 & 65.1 \\
\hline 7 & None & 62.0 & 60.9 \\
\hline 8 & None & 62.6 & 61.8 \\
\hline
\end{tabular}




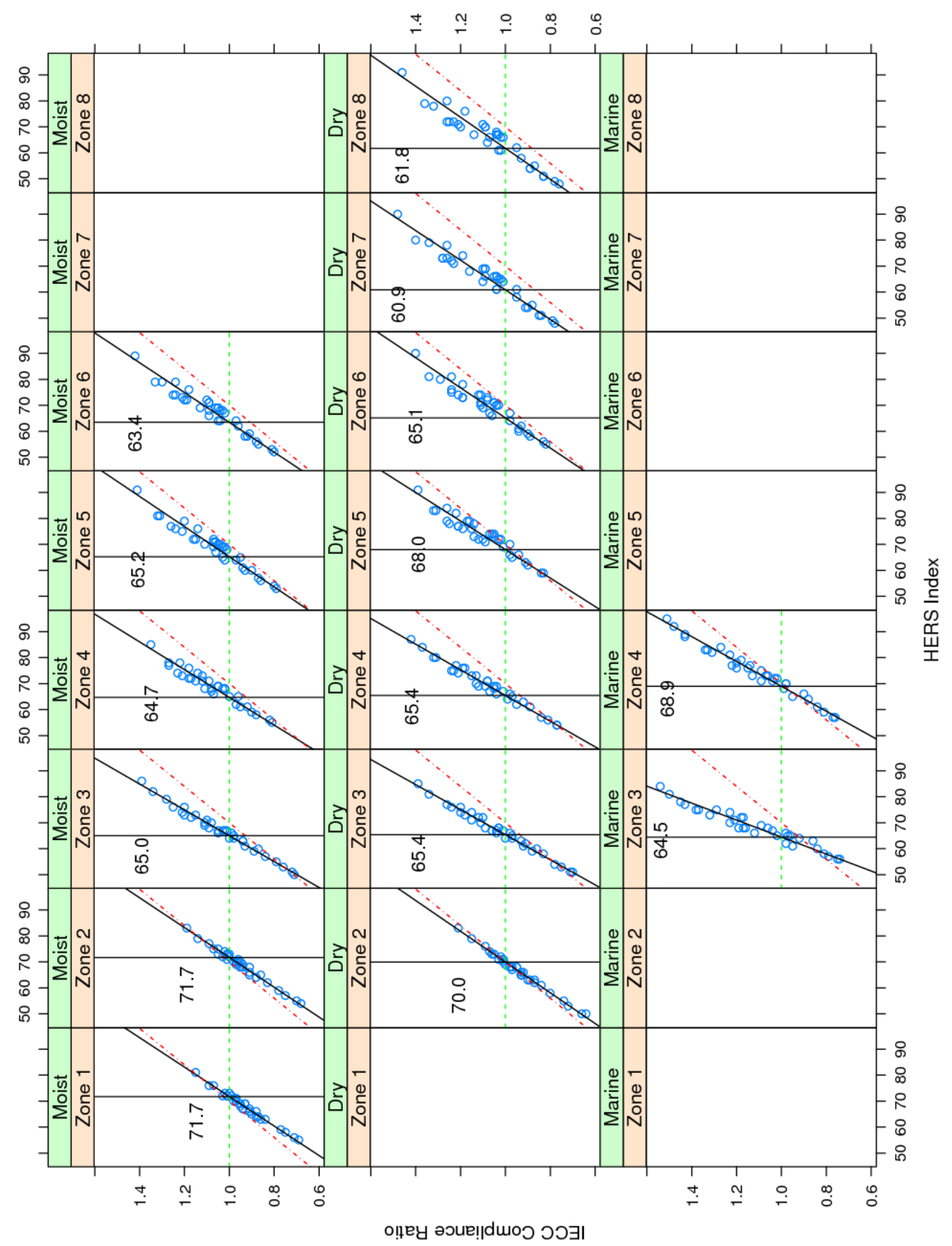

Figure 3.8. 2012 IECC Compliance Ratio versus HERS Index for Homes with Automatic Setback Thermostats by Climate Zone and Moisture Regime 


\subsection{Results, Conclusions, and Recommendations}

These analyses cover several of the major differences between the HERS Index and code compliance as defined by the 2012 IECC. Because the analyses have not addressed all the expected differences and have been conducted for a single building type and heating fuel/system, the results should be considered to be illustrative only. They represent reasonable Corresponding HERS Index values for the prototype home evaluated here- a single-family, gas-heated, $2400-\mathrm{ft}^{2}$ home with a crawlspace foundation and federal-minimum HVAC and water heating efficiencies. These Corresponding HERS Index values, which include downward adjustments to account for automatic setback thermostats, are shown in Table 4.1.

Table 4.1. Preliminary Corresponding HERS Index Values ${ }^{1}$

\begin{tabular}{clc}
\hline $\begin{array}{c}\text { Climate Zone and } \\
\text { Moisture Regime }\end{array}$ & $\begin{array}{c}\text { Corresponding } \\
\text { HERS Index }\end{array}$ \\
\hline 1 & Moist & 71.7 \\
2 & Moist & 71.7 \\
2 & Dry & 70.0 \\
3 & Moist & 65.0 \\
3 & Dry & 65.4 \\
\hline 3 & Marine & 64.5 \\
4 & Moist & 64.7 \\
4 & Dry & 65.4 \\
4 & Marine & 68.9 \\
5 & Moist & 65.2 \\
5 & Dry & 68.0 \\
6 & Moist & 63.4 \\
6 & Dry & 65.1 \\
\hline 7 & & 60.9 \\
8 & & 61.8 \\
\hline
\end{tabular}

Several observations, indications, and caveats are brought to light from these analyses:

- The HERS Index and the 2012 IECC Compliance Ratio are systematically and cleanly correlated for the set of configurations examined. Although the two metrics are based on different calculated values (nMEUL versus annual energy costs), a relative change in one metric corresponds to a similar relative change in the other. Although there is scatter around the line of correspondence between the two metrics, it is not excessive and not systematically biased.

- The Corresponding HERS Index values are not necessarily close to the commonly expected value of 70 , which is based on an understanding of the respective code baselines of the two metrics. Rather, the complying values can be either higher or lower than 70 and can differ by as much as five to eight HERS points for the specific prototype home evaluated here. Differences between the metrics not analyzed here will no doubt result in additional differences to the Corresponding HERS Index values.

\footnotetext{
${ }^{1}$ Recall that the HERS standards require integral HERS Index values. The Index values in Table 4.1 retain one decimal place of precision for a more detailed presentation of the analytical results.
} 
- Differences in the treatment of mechanical ventilation by the two metrics are irrelevant to code compliance, provided a state or jurisdiction enforces the 2012 IECC requirement for mechanical ventilation. If the requirement was eliminated or not enforced, a HERS compliance path based on the Corresponding HERS Index values shown in Table 4.1 could result in significantly less efficient envelopes than other compliance paths.

- Differences in the treatment of thermostat setpoints by the two metrics result in minimal impact on the energy-performance correlation between the HERS Index and the Compliance Ratio and the Corresponding HERS Index values computed from this analysis.

- Differences in the treatment of automatic setback thermostat credits by the two metrics result in a systematic overestimation of energy performance by the HERS Index compared to the IECC Compliance Ratio. Consequently, Corresponding HERS Index values used in a HERS Index-based compliance path should be lowered by about two points. (Table 4.1 reflects this adjustment.)

- Corresponding HERS Index values vary by climate zone and moisture regime. It seems clear that a HERS compliance path would need to specify different Corresponding HERS Index values for each zone and regime. This is not problematic, except that the 2012 IECC currently has no requirements that vary by moisture regime, so this discriminator might be unfamiliar to builders and code officials. The Corresponding HERS Index values might need to vary with other parameters such as building type and size, glazing area, and perhaps other climate parameters.

- Although the methodology developed for this analysis was effective, it could be simplified to facilitate analysis of a broader range of house characteristics:

o The use of 33 house configurations to define the line of correspondence between the IECC Compliance Ratio and the HERS Index is overkill. Considerably fewer configurations need to be simulated to confidently characterize the relationships.

o Modifying the definition of the HERS rule set to evaluate hypothetical HERS Index outcomes under IECC-defined rules is effective for the house characteristics evaluated in this study, but probably unnecessary for most house characteristics. Direct comparisons of IECC Compliance Ratios and HERS Indexes calculated for specific homes would be a more straightforward approach to analyzing house characteristics that are not directly reflected in the two metrics' definitions (e.g., house size, building type, glazing area). 


\subsection{References}

ASHRAE - American Society of Heating, Refrigerating and Air-Conditioning Engineers. 2001. 2001 ASHRAE Handbook: Fundamentals. Atlanta, Georgia.

Briggs RS, RG Lucas, and ZT Taylor. 2002. "Climate Classification for Building Energy Codes and Standards: Part 2- Zone Definitions, Maps, and Comparisons.” ASHRAE Transactions 109 Part 1.

Fairey P. 2009. Analysis of the ENERGY STAR Reference Home Concept as Proposed for EPA's 1011 National Program Requirements. FSEC-RR-342-09, Florida Solar Energy Center, Cocoa, Florida.

Fairey P, J Tait, D Tracey, M Holtz, and R Judkoff. 2000. The HERS Rating Method and the Derivation of the Normalized Modified Loads Method. FSEC-RR-54-00, Florida Solar Energy Center, Cocoa, Florida.

Fairey P, C Colon, E Martin, and S Chandra. 2006. Comparing Apples, Oranges and Grapefruit: An Analysis of Current Building Analysis Standards for Building America, Home Energy Ratings, and the 2006 International Energy Conservation Code. FSEC-CR-1650-06, Florida Solar Energy Center, Cocoa, Florida.

Lucas R. 2009. Determination for the 2006 International Energy Conservation Code, Residential Buildings - Technical Support Document. PNNL-18806, Pacific Northwest National Laboratory, Richland, Washington.

Lucas RG, T Taylor, V Mendon, and S Goel. 2012. National Energy and Cost Savings for New Singleand Multifamily Homes: A Comparison of the 2006, 2009 and 2012 Editions of the IECC. PNNL-21329, Pacific Northwest National Laboratory, Richland, Washington.

RESNET - Residential Energy Services Network. 2012. “HERS Rater Information.” Accessed August 26, 2012, at http://www.resnet.us/professional/rater/what-is-a-hers.

RESNET - Residential Energy Services Network. 2013. Mortgage Industry National Home Energy Rating Systems Standards. Accessed July 1, 2013, at http://www.resnet.us/standards/RESNET_Mortgage Industry National_HERS Standards.pdf.

Taylor T, N Fernandez, and R Lucas. 2012. Methodology for Evaluating Cost-Effectiveness of Residential Energy Code Changes. PNNL-21294, Pacific Northwest National Laboratory, Richland, Washington.

U.S. Environmental Protection Agency (EPA). 2009. “Overview of Evolving Energy Star Qualified Homes Program \& Methodology for Estimating Savings.” PDF version can be downloaded from the Internet. Type or paste document title into search engine and run search.

U.S. Environmental Protection Agency (EPA). 2011. "EPA Response to RESNET's Comments on the Proposed Energy Star 2011 Qualified New Homes.” PDF version can be downloaded from the Internet. Type or paste document title into search engine and run search. 
U.S. Environmental Protection Agency (EPA). 2012. "ENERGY STAR Qualified Homes, Version 3 (Rev. 05) HERS Index Target Procedure for National Program Requirements.” PDF version can be downloaded from the Internet. Type or paste document title into search engine and run search. 



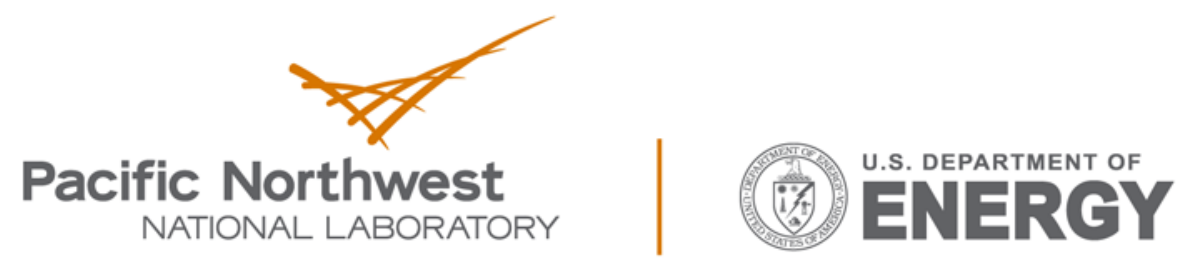

Proudly Operated by Battelle Since 1965

902 Battelle Boulevard

P.O. Box 999

Richland, WA 99352

1-888-375-PNNL (7665)

www.pnnl.gov 